23 Grossman, A., and Boctor, A., Proc. US Nat. Acad. Sci., 69, 1161 (1972).

${ }^{24}$ Panko, W. B., and Kenney, F. T., Biochem. Biophys. Res. Commun., 43, 346 (1971).

${ }^{25}$ Cavia, E., and Webb, T. E., Biochim. Biophys. Acta, 262, 546 (1972).

${ }^{26}$ Chuah, C.-C., Holt, P. G., and Oliver, I. T., Intern. J. Biochem., 2, 193 (1971)

27 Grossman, A., and Mavrides, C., J. Biol. Chem., 242, 1398 (1967).

${ }^{28}$ Kenney, F. T., Science, 156, 525 (1967).

29 Schimke, R. T., Nat. Cancer Inst. Monograph, 27, 301 (1967).

30 Reel, J. R., and Kenney, F. T., Proc. US Nat. Acad. Sci., 61, 200 (1968).

${ }^{31}$ Thompson, E. B., Granner, D. K., and Tomkins, G. M., J. Mol. Biol., 54, 159 (1970).

\section{Cholinesterase Inhibitors: Structure of Eserine}

ESERINE (physostigmine) was first isolated from the Calabar bean in the latter half of the last century ${ }^{1}$, but it was not until much later that its activity on the heart was demonstrated to be due to inhibition of acetylcholinesterase ${ }^{2,3}$. It is one of the few compounds that are equally active as inhibitors of both true and pseudo-cholinesterase and has been used by many workers as a reference standard in the evaluation of new cholinesterase inhibitors. The chemical structure of this alkaloid was elucidated by Stedman ${ }^{4}$ and the absolute configuration has relatively recently been confirmed by use of the nuclear Overhauser effect (NOE) in NMR spectroscopy 5 . As part of our study of the geometry of molecules affecting cholinergic nervous transmission, we have determined the crystal structure. ment with the results of the NOE study ${ }^{5}$. In solution there is no inversion of configuration by $\mathrm{Cl} 8$ and the lone pair on N5 (ref. 5), but the second pyrrolidine ring may be expected to be conformationally rather flexible because of inversion through N7. In the crystal, the lone pair on N7 is also cis to the hydrogen atom on C6. The carbamate group is planar, with the hydrogen on N16 trans to the keto oxygen, and will remain so in solution because of the partial double bond C14-N16. In the crystal, the torsion angle C12-C1-O13-C14 is observed to be $-72^{\circ}$, but an examination of CPK spacefilling atomic models indicates that this angle may range $-30^{\circ}$ to $-150^{\circ}$ and $+30^{\circ}$ to $+150^{\circ}$ : the value of 31.8 observed by us in the crystal structure of neostigmine bromide ${ }^{7}$ is clearly a lower bound and no sign of a similar interaction between the ortho aromatic proton and the keto oxygen exists in the present structure.

Chothia and Pauling ${ }^{8}$ have postulated a particular conformation of acetylcholine as being the conformation relevant to interaction with the esterase, and Pauling and Petcher ${ }^{7}$ have pointed out the similarity between this postulated conformation and the observed solid-state conformation of neostigmine. It is difficult to correlate the conformation of eserine with these two because of the para relationship of N5 and the carbamate group in eserine. The observed conformations of eserine and neostigmine are, however, similar in some respects. The N5$\mathrm{C} 14$ and N5-O15 distances are 638 and 620 pm respectively, compared with 605 and $647 \mathrm{pm}$ in neostigmine. AChE appears to be relatively insensitive to molecular shape as far as reversible inhibition is concerned, provided that three necessary groups are present, these being a carbamate group bonded to an aromatic ring which must carry an alkyl substituted nitrogen atom in the meta or para position.

We thank Dr Hanspeter Weber for making available to us
Fig. 1 Perspective drawing of eserine, projected on the plane of $\mathrm{N} 5-\mathrm{N} 7-\mathrm{C} 9-\mathrm{C} 11$. The absolute configuration corresponds to that of the natural alkaloid.

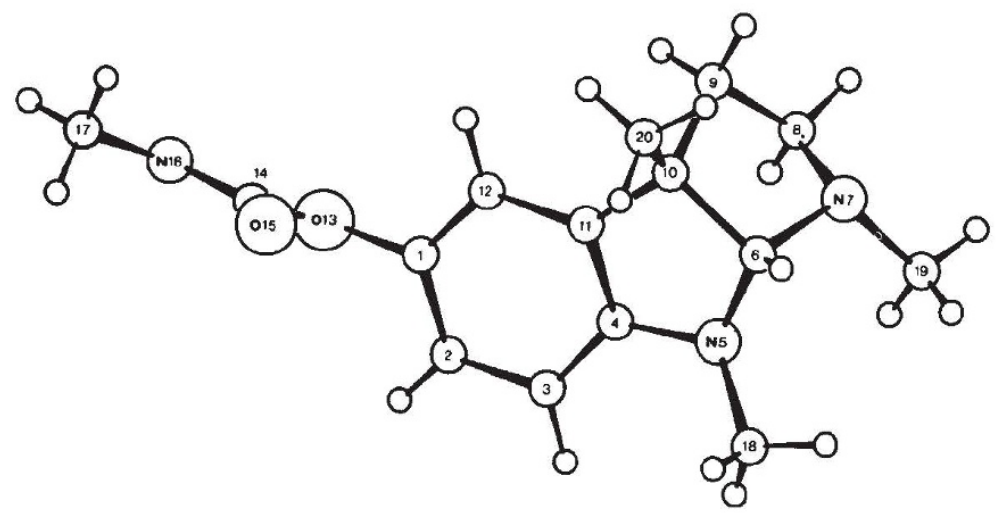

Crystals of eserine (BDH Ltd), as clear tabular plates, are orthorhombic, space group $\mathrm{P} 22_{1} 2_{1}$, with $a=1458$ (1), $b=$ 1435 (1), $c=727.1$ (6) pm. Three-dimensional intensity data were measured on a computer-controlled ${ }^{6}$ four-circle diffractometer using graphite monochromatized $\mathrm{MoK}_{\mathrm{a}}$ radiation. 2,658 measurements for $2 \theta \leq 60^{\circ}$ yielded 2,556 symmetryindependent observations, of which 1,520 were significantly above background $(I \geq 3 \sigma(I))$. The structure was solved by application of multi-solution direct methods and refined by block-diagonal least squares using anisotropic temperature factors for $\mathrm{C}, \mathrm{N}$ and $\mathrm{O}$, and isotropic vibrations for hydrogen. The present values of $R$ are 0.060 over the 1,520 significant reflexions and 0.097 over all 2,531 data.

The conformation of the molecule is shown in Fig. 1, in the absolute configuration corresponding to that of the natural alkaloid. The two pyrrolidine rings are cis-fused, and that adjacent to the aromatic ring is practically flat, while the other is in the half-chair $\left(C_{2}\right)$ conformation with the two-fold axis passing through $\mathrm{C} 8$ and the centre of the $\mathrm{C} 6-\mathrm{C} 10$ bond. Both ring nitrogen atoms are tetrahedral, but $\mathrm{N} 5$ is rather flattened and has more $s p^{2}$ character, judging from the bond angles. The C18 methyl group is cis to the hydrogen on C6, in agree- his direct methods phasing programs and the MRC for financial support.

William Ramsay, Ralph Forster and

T. J. PETCHeR *

P. Pauling

Christopher Ingold Laboratories,

University College London,

Gower Street,

London WC1

Received July 17, 1972.

* Present address: Research Laboratories for Pharmaceutical Chemistry, Sandoz Ltd, Basle, Switzerland.

1 Hesse, O., Liebig's Ann. Chem., 192, 175 (1878).

2 Engelhart, E., and Loewi, O., Arch. Exp. Pathol. Pharmakol., 150, 1 (1930).

${ }^{3}$ Matthes, K., J. Physiol., 70, 338 (1930).

4 Stedman, E., and Barger, G., J. Chem. Soc., 247 (1925).

5 Newcome, G. R., and Bhacca, N. S., Chem. Commun., 385 (1969).

6 Busing, W. R., Levy, H. A., Ellison, R. B., King, S. P., and Roseberry, R. T., ORNL-4143 (1968).

8 Chothia, C. H., and Pauling, P., Nature, 223, 919 (1969).
${ }_{7}$ Pauling, P., and Petcher, T. J., J. Med. Chem., 14, 1 (1971). 